\title{
Role of Clinical Pharmacist in Context of World Health Organization against COVID-19
}

\author{
Majid Khan \\ Department of Pharmacy, Shaheed Benazir Bhutto University, Sheringal Dir Upper Khyber, Pakhtunkhwa, PAKISTAN.
}

\section{Dear Editor,}

Since December 2019, the outbreak of novel human virus on the name of COVID-19 spread in China from Wuhan city around the world to 183 countries in 2020. ${ }^{[1]}$ This virus considered lethal for many people. Most of the people who infected get respiratory symptoms include cough, shortness of breath, sneezing and fever. The novel virus transmitted in contact person to person via droplets of cough or sneezes from infected person or animal. High risks to those peoples who are in outbreak areas or with other complications include immune-compromised patients, diabetes mellitus, cardiac diseases and any other co-morbidities. ${ }^{[2]}$ Clinical Pharmacists are more easily accessible healthcare professionals to public and key figures of health care team regarding infectious diseases. According to Amir M et al. Clinical Pharmacy is the liaison of pharmacist with physician in which Clinical pharmacists prescribing medications. ${ }^{[3,4]}$ Wasim et al. articulated that Clinical Pharmacists are independent prescribers in United Kingdom. ${ }^{[5]}$ In current pandemic pharmacists may consider secondary prescriber due to physician's self-illness and inpatient focuse. ${ }^{[1]}$ World Health Organization being a standard organization around the world providing health to worldwide population, mandate some qualities upon the Pharmacists that a good pharmacist bears seven qualities every quality called as star thus named as "Seven stars Pharmacist" includes communicator, teacher, decision maker, leader, manager, lifelong learner, caregiver ${ }^{[[]}$additional two are researcher and pharmapreneur thus total becomes "Nine stars Pharmacist" (Figure 1), almost all of these are implemented in developed countries in outbreak of novel corona virus which was expected WHO few years ago now the time for these professionals proving their selves.
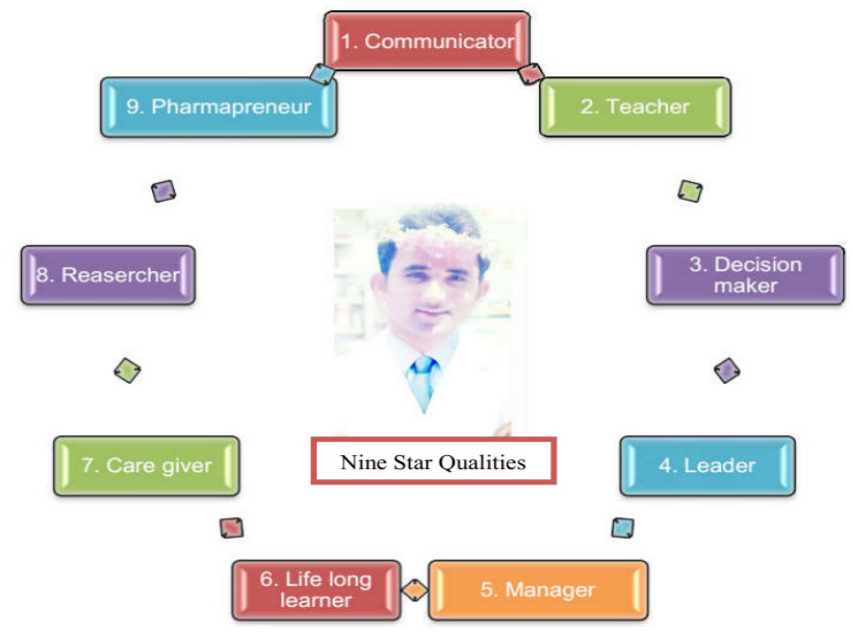

Figure 1: Clinical Pharmacist qualities for controlling COVID-19.
The scope of Clinical Pharmacist is broader and almost in all health care system even from drug development to their real-world maintenance (Pharmaceutical Care). Clinical Pharmacist is one of the angle of triangle with physician and nurse without Clinical Pharmacist health care team triangle is incomplete, but in under developed countries like Pakistan, Bangladesh, Malaysia and many others. Clinical Pharmacists are considered fragile in health care team. ${ }^{[7]}$ This bit of study through light on actual: (i) role of Clinical Pharmacist which was expected by World Health Organization from them; (ii) to aware public regarding third important angle of health team triangle; as well as (iii) request to high authorities to hire them on front line like developed countries.

Clinical Pharmacists are providing information's to every person in community including health practitioners (physician and nurse) about drugs of choice in fever, cough and other symptoms of virus in proper dose as well as their interactions. Also providing information's to public about this disease that how this happen? Which part of the body effect? How to protect yourself from the attack of this virus? CPs also communicating strategies for prevention recommended by WHO includes; keep social distancing, stay home, avoid hand shaking, regular hand wash with soap, use mask, reduce transmission from animals and isolate infected patient in early diagnose. These information's communicating as expected by World Health Organization in seven stars. ${ }^{[1,7,8]}$

The key role of Clinical Pharmacist to be a competent teacher and competency is coming from current studies. CPs is teaching to patients regarding medications in COVID-19. Also teaching to public on social media about sanitizer's preparation by World Health Organization recommended formula. ${ }^{[1,7]}$

Leader leads generations; Clinical Pharmacist leading the public and other health practitioners in quarantine as well as on social media and will cope the novel virus in this way will lead the generations.

Management is not only limited to managers but it is coming from birth to death. Clinical Pharmacist bearing light of management to shine the dark brought by Coronavirus because the shortage of medicines may occur due to prolong pandemic and hindrance in supply from enriched basic manufacturing countries India and China and thus Pharmacists proactively promoting strategies for managing drugs according to American Society of Health-System Pharmacists. If shortage occurs the patients will receive sub-therapeutic doses thus the criteria of "health for all "will not be fulfilled. CPs also instructing public to limit unnecessary use of PPEs, conversion of intravenous to per os rather than emergency situations, this is proof to the world that Clinical Pharmacist working as a manager. 
Knowledge is the type of wheel and Holy Prophet (PBUH) narrated that learn knowledge from "cradle to grave" and old is gold thus senior CPs are cordially involved for designing the drugs in clinical trials due to their long time learning in order handle this emergency. ${ }^{[1,6,7]}$

In developed countries CPs providing care to the patients in the form of Pharmaceutical Care because nowadays the paradigm shift in pharmacy practice from mercantile practice to patient oriented. ${ }^{7}$ Lockdown negatively affected the chronic diseases patients thus CPs contacts with patients at home and providing counseling like in hypertension with B.P systolic more than $180 \mathrm{~mm} \mathrm{Hg}$ and diastolic more than $110 \mathrm{~mm} \mathrm{Hg}$, diabetes mellitus more than $180 \mathrm{mg} / \mathrm{dl}$ at random range, counseling patients online for administration of insulin, regular checking of blood pressure and blood glucose level, diet counseling, prefer exercise for $30 \mathrm{~min}$ daily, interactions between drugs which can worse the conditions can be avoided, like Warfarin causes bleeding when use without managing of Interactional Normalized Ratio thus CP recommends INR to patients who are administering anti-coagulants therapy. ${ }^{[4]}$

Designing of novel targeted drug delivery is coming under the domain of CPs; thus they are trying against novel virus to save the lives because it is mentioned in Holy Quran that "any one of you saved a life, it means he saved the humanity". ${ }^{[9]}$ FDA till now did not successfully approved targeted drug against corona virus. Clinical Pharmacists are working with in liaison with other health care team and utilized the drug Chloroquine for previous outbreak of this virus, similarly in this outbreak Hydroxychloroquine considered relatively better choice, beside this ritonavir, immune-modulating agents, interferon's, remdesivir, providing passive immunity, disinfectants from herbal sources, gargles preparation, Ivermectin insecticidal for blocking corona virus got effective in vitro approach but requirement for complete blocking of biosynthetic pathway, then Dexamethasone for cytokines storm thus no successful treatment that's why research is still continued..$^{[7,10]} \mathrm{CP}$ working as a pharmapreneur means introducing new gadgets for controlling the emergency situation like personal protective equipment and sanitizers manufacturing in short time with low expenses. ${ }^{[11,12]}$

Being an owner of life saving profession, Pharmacists utilizes knowledge against novel corona virus in the context of World Health Organization and International Pharmaceutical Federation. God has willed it, Pharmacists will develop targeted rational drugs and will successfully eradicate corona virus from the world.

\section{ACKNOWLEDGEMENT}

The author is extremely acknowledged to Pharmacists and other heroes of health care team who are fighting on frontline in warm war of COVID-19.

\section{ABBREVIATIONS}

CP: Clinical Pharmacist; PBUH: Peace be upon Him; B.P: Blood pressure; FDA: Food and Drugs Administration.

\section{REFERENCES}

1. Alan E. Gross, Conan MacDougall, Roles of the clinical pharmacist during the COVID-19 pandemic, editorial. J Am Coll Clin Pharm. 2020;1-3. DOI: 10.1002/ jac5.1231

2. Li Q, Guan X, Wu P, et al. Early Transmission Dynamics in Wuhan China of Novel Corona-virus Infected Pneumonia. The New Eng Journal of Med. 2020. DOI: 10.1056/NEJMoa2001316.

3. Amir M. Clinical pharmacy practice: An activity based definition for pharmacy students of developing countries. Archives of Pharmacy Practice. 2012;3(3):193.

4. Zheng SQ, Yang L, Zhou PX, Li HB, Liu F, Zhao RS. Recommendations and guidance for providing pharmaceutical care services during COVID-19 pandemic: A China perspective. Research in Social and Administrative Pharmacy. 2020.

5. Wasim B, Richardson MD. A brief history of Pharmacist Prescribing in the United Kingdom: Draft, country focuses. Euro Journal of Hosp Pharmacy. 2012;19(5):487-8.

6. Thamby SA, Subramani P. Seven-Star Pharmacist Concept by World Health Organization. J Young Pharmacist. 2014;6:2.

7. Khan M, Riaz M. Strategic Assessment of Challenges to Clinical Pharmacists in Pakistan and their Historical Relationship with Physicians. J Pharm Pract Community Med. 2020;5(3):69-74.

8. World Health Organization. Infection prevention and control during health care when COVID-19 is suspected https://www.who.int/publications-detail/infectionprevention-and-control-during-health-care-when-novel-coronavirus-(ncov)infection-is-suspected-20200125

9. Holy Quran, Ayah number 32, Surrah Al-Maida, $6^{\text {th }}$ Parah.

10. Shen K, Yang Y, Wang T, Zhao D, Jiang Y, Jin R, et al. Diagnosis, treatment and prevention of 2019 novel coronavirus infection in children: Experts' consensus statement. World Journal of Pediatrics. 2020;7:1-9.

11. Parasuraman S. The Nine-star Pharmacist: An overview. JYP. 2015;7(4):1-4.

12. ASHP. Pharmacy Readiness for Corona virus disease, recommendations for state policy makers. 2020. ashp.org/coronavirus.

Received: 15 August 2020; Accepted: 21 September 2020

Correspondence:

Dr. Majid Khan

Department of Pharmacy,

Shaheed Benazir Bhutto University, Sheringal Dir Upper Khyber Pakhtun Khwa, PAKISTAN.

Email: majidkhanpiran@gmail.com

Cite this article as: Khan M. Role of Clinical Pharmacist in Context of World Health Organization against COVID-19. J Pharm Pract Community Med. 2020;6(3):44-5. 